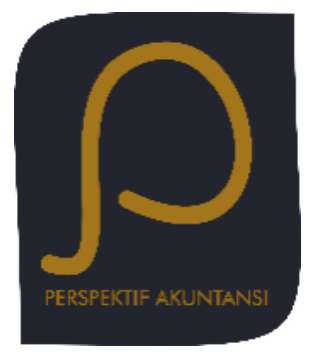

Perspektif Akuntansi

Volume 1 Nomor 1 (Oktober 2018), hal. 21-37

ISSN: 2623-0194(Print), 2623-0186(Online) Copyright $(\mathrm{C}$ The Authors(s). All Rights Reserved

Fakultas Ekonomika dan Bisnis,

Universitas Kristen Satya Wacana

DOI: https://doi.org/10.24246/persi.v1i1.p21-37

http://ejournal.uksw.edu/persi

\title{
Dimensi Kualitas Pelayanan, Kepuasan dan Kepatuhan Pajak
}

\author{
Nita Anggraheny Savitri \\ Universitas Kristen Satya Wacana \\ Theresia Woro Damayanti ${ }^{1}$ \\ Universitas Kristen Satya Wacana
}

Received Abstract. This study is conducted to identify the effect of service quality 21/05/2018 dimensions given by tax officials to the satisfaction and compliance of individual taxpayers. Service quality dimensions are measured by five

Accepted points, tangibles, reliability, responsiveness, assurance and empathy of

21/06/2018 respondents. Data obtained in the form of primary data from 125 questionnaires using Convenience Sampling method. Research data then tested by using Partial Least Square. This research shows that the dimension of service quality consists of tangibles, reliability, responsiveness, assurance, and empathy have no significant effect to taxpayer compliance through service satisfaction, but service quality dimension have a direct and significant effect on taxpayer compliance. This means that personal taxpayer compliance is influenced by the quality of service.

Keywords: Service quality dimension, taxpayer's satisfaction, taxpayer compliance.
Abstrak. Penelitian ini bertujuan untuk menguji pengaruh dimensi kualitas pelayanan yang diberikan aparat pajak terhadap kepuasan dan kepatuhan wajib pajak orang pribadi. Dimensi kualitas pelayanan diukur berdasarkan lima hal, bukti fisik, kehandalan, daya tanggap, jaminan dan empati responden. Data yang didapat berupa data primer yang berasal 125 wajib pajak dengan menggunakan metode Convenience Sampling. Data penelitian kemudian dianalisis dengan menggunakan Partial Least Square. Hasil penelitian ini menunjukkan

${ }^{1}$ woro@staff.uksw.edu 
bahwa dimensi kualitas pelayanan yaitu bukti fisik, kehandalan, daya tanggap, jaminan, dan empati tidak berpengaruh secara signifikan terhadap kepatuhan wajib pajak melalui kepuasan pelayanan, tetapi dimensi kualitas pelayanan tersebut berpengaruh langsung dan signifikan terhadap kepatuhan wajib pajak. Hal ini berarti bahwa kepatuhan wajib pajak orang pribadi dipengaruhi oleh kualitas pelayanan.

Kata kunci: Dimensi kualitas pelayanan, kepuasan wajib pajak, kepatuhan wajib pajak orang pribadi.

\section{Pendahuluan}

Pemerintah Indonesia sejak tahun 2002 melaksanakan kebijakan reformasi perpajakan. Kebijakan ini diambil karena tingkat kepercayaan masyarakat yang masih rendah terhadap sistem perpajakan sementara beban pengamanan penerimaan negara terhadap pajak terus meningkat (Direktorat Jendral Pajak, 2008). Salah satu upaya dalam reformasi perpajakan adalah dengan moderinasisi administrasi perpajakan. Dalam modernisasi administrasi perpajakan ini, terjadi perubahan paradigma terhadap wajib pajak, yaitu wajib pajak dianggap sebagai mitra dan pelanggan oleh Direktorat Jendral Pajak. Dengan paradigma ini, maka peningkatan pelayanan kepada wajib pajak merupakan pusat dari modernisasi perpajakan (Fasmi \& Misra, 2014). Dengan meningkatnya pelayanan kepada wajib pajak diharapkan akan meningkatkan kepatuhan pajak (Direktorat Jendral Pajak, 2008). Paradigma ini memandang bahwa kepatuhan wajib pajak tidak hanya dipengaruhi oleh faktor wajib pajak itu sendiri, tetapi kepatuhan muncul sebagai respon atas pelayanan prima oleh aparat pajak (Fasmi \& Misra, 2014). Supadmi (2009) juga mengemukakan bahwa peningkatan kualitas pelayanan perpajakan merupakan salah satu faktor dari kepatuhan wajib pajak.

Pelayanan yang diberikan selama proses perpajakan berkaitan dengan kepatuhan wajib pajak, artinya semakin baik pelayanan yang diberikan maka akan membentuk kepatuhan yang tinggi dari wajib pajak (Worsham \& Ronald, 2006). Sebaliknya, apabila pelayanan yang diberikan fiskus buruk maka wajib pajak enggan membayar pajak. Beberapa kajian penelitian sebelumnya tentang pengaruh pelayanan perpajakan terhadap kepatuhan wajib pajak menunjukkan bahwa dalam rangka meningkatkan kepatuhan wajib pajak, kualitas pelayanan pajak juga harus ditingkatkan guna memenuhi kewajiban perpajakannya (Nurhayati, halimatusadiah, \& Diamonalisa, 2015). Frecknall-Hughes \& Moizer (2015) juga mengungkapkan bahwa kualitas pelayanan pajak berpengaruh positif dan signifikan terhadap kepatuhan wajib pajak. 
Berbagai penelitian menunjukkan bahwa kualitas pelayanan memberikan dampak positif terhadap kepatuhan pajak (Mustaphaa \& Obid, 2014; Awaluddin \& Tamburaka, 2017; Silalahi, Musadieq, \& Nurtjahjono, 2015). Akan tetapi penelitian tentang kualitas pelayanan tersebut belum memisahkan kualitas pelayanan kedalam lima dimensi pelayanan seperti yang diungkapkan oleh Zeithaml, Valarie, Berry, \& Leonard (2003). Padahal, pemisahan dimensi kualitas pelayanan tersebut dapat digunakan bagi aparatur pajak untuk menentukan sikap dalam mempertahankan dan meningkatkan kinerja dalam melayani wajib pajak. Zeithaml, Valarie, Berry, \& Leonard (2003) mengungkapkan bahwa pelayanan dianggap berkualitas apabila dapat diukur melalui lima dimensi, yaitu bukti fisik (tangibles), daya tanggap (responsiveness), kehandalan (reliability), jaminan (assurance), dan empati (empathy).

Selain itu, terdapat kemungkinan kualitas pelayanan berpengaruh pada kepatuhan pajak namun melalui kepuasan, seperti yang dikemukakan Kotler (2003) bahwa suatu pelayanan yang berkualitas akan menyebabkan seseorang merasa puas dengan jasa yang diberikan. Oleh sebab itu, dalam kaitannya dengan perpajakan, kualitas pelayanan akan menyebabkan kepuasan bagi wajib pajak terlebih dahulu sebelum wajib pajak menjadi patuh. Hal ini diperkuat oleh penelitian Jaya, Ratnawati, \& Sardjono (2017) serta Walsh (2012) yang menunjukkan bahwa kepuasan wajib pajak akan berpengaruh terhadap kepatuhan pajak.

Studi ini bertujuan menguji dampak langsung dari dimensi kualitas pelayanan terhadap kepatuhan pajak maupun tidak langsung melalui kepuasan wajib pajak sebagai variabel intervening. Hasil penelitian ini diharapkan dapat memberikan informasi tentang dimensi kualitas pelayanan apa saja yang dapat mempengaruhi kepatuhan membayar pajak guna mengoptimalkan kinerja dalam memungut pajak sebagai sumber utama penerimaan negara. Selain itu, penelitian ini juga diharapkan memberikan bukti empiris peran dari kepuasan pajak sebagai variabel intervening dalam pengujian kepatuhan pajak.

\section{Telaah Pustaka}

\section{Kualitas Pelayanan}

Kualitas pelayanan pajak adalah kemampuan dari Direktorat Jenderal Pajak dalam bentuk pelayanan pajak yang prima kepada wajib pajak sehingga wajib pajak merasa puas terhadap pelayanan yang diberikan oleh Direktorat Jenderal Pajak. Dalam memenuhi kewajiban perpajakannya terdapat beberapa cara yang dapat digunakan untuk meningkatkan kualitas pelayanan yaitu dengan meningkatkan kemampuan teknis pegawai dalam berbagai bidang, salah 
satunya bidang perpajakan, perbaikan infrastruktur, serta memberikan kemudahan dalam penggunaan sistem informasi dan teknologi kepada para wajib pajak (Supadmi, 2009).

Terdapat beberapa ukuran yang dapat digunakan dalam menilai kualitas pelayanan. Menurut Zeithaml, Valarie, Berry, \& Leonard (2003), terdapat lima dimensi yang dapat digunakan untuk mengukur kualitas pelayanan, yaitu bukti fisik, daya tanggap, kehandalan, jaminan, dan empati. Bukti fisik merupakan bagaimana para pegawai mampu menunjukkan keberadaan yang sebenarnya pada pihak eksternal, yang dapat meliputi: fasilitas fisik (gedung, gudang dan lainnya), perlengkapan dan peralatan yang dipergunakan (teknologi), serta penampilan karyawannya. Sementara daya tanggap diartikan sebagai sikap tanggap dalam membantu maupun memberikan pelayanan yang cepat dan tepat kepada pelanggan, dengan cara penyampaian informasi yang jelas.

Kehandalan mencerminkan kemampuan untuk memberikan pelayanan jasa yang telah dijanjikan kepada wajib pajak secara tepat, konsisten dan terpercaya, misal: ketepatan waktu, pelayanan yang sama untuk semua pelanggan, dan sikap simpatik. Jaminan menunjukkan bagaimana cara menumbuhkan rasa percaya pelanggan terhadap kemampuan, kesopanan, dan pengetahuan yang dimiliki setiap pegawai. Terdapat beberapa komponen yang dianggap dapat menumbuhkan rasa percaya pelanggan yaitu kompetensi artinya pengetahuan yang dimiliki oleh para petugas untuk melakukan pelayanan, kesopanan yang meliputi keramahan, perhatian dan sikap para petugas, serta kredibilitas yang didefinisikan sebagai segala hal yang berhubungan dengan kepercayaan kepada perusahaan, seperti reputasi maupun prestasi. Sementara empati adalah pemberian perhatian yang bersifat individual seperti memahami kebutuhan dan keinginan pelanggan.

\section{Kepuasan Pelayanan Wajib Pajak}

Secara sederhana kepuasan pelanggan dapat terpenuhi apabila kebutuhan, keinginan, serta harapan pelanggan sesuai dengan realita dari produk yang mereka konsumsi. Menurut Zeithaml, Valarie, Berry, \& Leonard (2003) kepuasan pelanggan merupakan evaluasi pelanggan atas produk dan jasa yang diterima apakah telah sesuai dengan kebutuhan dan harapan yang dimiliki pelanggan atau tidak.

Kepuasan merupakan tujuan utama pelayanan prima (Sutopo \& Suryanto, 2003). Untuk itu, suatu hal yang wajib dilakukan aparatur pelayanan adalah memuaskan pelanggannya. Aparatur pelayanan dapat mencapai kepuasan pelanggan dengan terlebih dulu mengetahui siapa pelanggannya sebagai cara untuk mengidentifikasi apa keinginan pelanggan. 


\section{Pengembangan Hipotesis}

\section{Pengaruh Dimensi Kualitas Pelayanan Terhadap Kepatuhan Wajib Pajak}

Pelayanan yang baik dari aparatur pajak merupakan hal penting untuk dapat menarik perhatian para wajib pajak. Pelayanan pajak dapat berupa fasilitas maupun kegiatan yang mendukung wajib pajak agar lebih mudah melaksanakan kewajibannya membayar pajak, seperti menyediakan sarana dan prasarana yang dibutuhkan wajib pajak atau yang paling penting yaitu adanya aparatur pajak yang dapat menjunjung tinggi integritas, akuntabilitas, dan transparansi sehingga menimbulkan kepercayaan dari wajib pajak itu sendiri. Hal ini sejalan dengan kajian penelitian sebelumnya yang dilakukan Mustaphaa \& Obid, (2014) yang menunjukkan bahwa kualitas pelayanan memiliki pengaruh positif terhadap kepatuhan. Hal yang sama juga ditunjukkan oleh penelitian yang dilakukan oleh Nurhayati, halimatusadiah, \& Diamonalisa (2015) yang membuktikan bahwa kualitas pelayanan perpajakan dan pelaksanaan sanksi pajak berpengaruh secara signifikan terhadap kepatuhan wajib pajak. Hasil penelitian tentang pengaruh kualitas pelayanan terhadap kepatuhan pajak juga ditunjukkan oleh Silalahi, Musadieq, \& Nurtjahjono (2015); Worsham \& Ronald (2006) serta Savitri (2016)

Dengan menggunakan lima dimensi kualitas pelayanan yang dikemukakan oleh Zeithaml, Valarie, Berry, \& Leonard (2003), yaitu bukti fisik, daya tanggap, kehandalan, jaminan dan empati maka hipotesis yang akan diuji adalah sebagai berikut:

$\mathrm{H}_{1 \mathrm{a}}$ : Dimensi kualitas pelayanan bukti fisik berpengaruh secara langsung terhadap kepatuhan wajib pajak

$\mathrm{H}_{1 \mathrm{~b}}$ : Dimensi kualitas pelayanan daya tanggap berpengaruh secara langsung terhadap kepatuhan wajib pajak

$\mathrm{H}_{1 \mathrm{c}}$ : Dimensi kualitas pelayanan kehandalan berpengaruh secara langsung terhadap kepatuhan wajib pajak

$\mathrm{H}_{1 \mathrm{~d}}$ : Dimensi kualitas pelayanan jaminan berpengaruh secara langsung terhadap kepatuhan wajib pajak

$\mathrm{H}_{1 \mathrm{e}}$ : Dimensi kualitas pelayanan empati berpengaruh secara langsung terhadap kepatuhan wajib pajak

\section{Pengaruh Dimensi Kualitas Pelayanan Terhadap Kepatuhan Wajib Pajak Melalui Kepuasan Wajib Pajak}

Feld \& Frey (2002) menjelaskan bahwa pelayanan perpajakan yang berkualitas akan mempengaruhi kepuasan wajib pajak sehingga pada gilirannya wajib pajak akan patuh terhadap kewajibannya untuk membayar pajak. Dengan demikian pelayanan perpajakan yang berkualitas akan meningkatkan 
kepuasan wajib pajak, dan akhirnya akan memberikan dampak terhadap meningkatnya kepatuhan wajib pajak.

Hal tersebut sejalan dengan hasil penelitian Walsh (2012) yang membuktikan secara empiris terdapat pengaruh antara kepuasan dan kepatuhan. Kajian penelitian sebelumnya yang dilakukan Jaya, Ratnawati, \& Sardjono (2017) juga menunjukkan bahwa kepuasan wajib pajak atas kinerja aparatur pajak berpengaruh secara signifikan terhadap kepatuhan wajib pajak. Hal ini menunjukkan semakin baik dan efektifnya kinerja pelayanan yang diberikan pegawai pajak dapat berpengaruh terhadap kepuasan yang dirasakan oleh wajib pajak, dan akan mempengaruhi kepatuhan wajib pajak dalam memenuhi kewajiban perpajakannya itu sendiri. Berdasarkan uraian di atas maka dapat ditarik hipotesis sebagai berikut:

$\mathrm{H}_{2} \mathrm{a}$ : Dimensi kualitas pelayanan bukti fisik berpengaruh tidak langsung terhadap kepatuhan wajib pajak melalui kepuasan wajib pajak

$\mathrm{H}_{2}$ b: Dimensi kualitas pelayanan daya tanggap berpengaruh tidak langsung terhadap kepatuhan wajib pajak melalui kepuasan wajib pajak

$\mathrm{H}_{2} \mathrm{C}$ : Dimensi kualitas pelayanan keandalan berpengaruh tidak langsung terhadap kepatuhan wajib pajak melalui kepuasan wajib pajak

$\mathrm{H}_{2} \mathrm{~d}$ : Dimensi kualitas pelayanan jaminan berpengaruh tidak langsung terhadap kepatuhan wajib pajak melalui kepuasan wajib pajak

$\mathrm{H}_{2} \mathrm{e}$ : Dimensi kualitas pelayanan empati berpengaruh tidak langsung terhadap kepatuhan wajib pajak melalui kepuasan wajib pajak

\section{Metoda}

Data yang digunakan dalam penelitian ini adalah data primer yang diperoleh melalui penyebaran kuesioner kepada wajib pajak yang telah terdaftar di KPP Pratama Salatiga. Wajib pajak orang pribadi usahawan dan pekerjaan bebas yang terdaftar dalam KPP Pratama Salatiga merupakan populasi di penelitian ini. Wajib pajak orang pribadi dalam kategori tersebut dipilih sebagai populasi sebab wajib pajak dalam kategori usahawan dan melakukan pekerjaan bebas melakukan kewajiban perpajakan dengan self assessment system, artinya wajib pajak aktif mulai dari menghitung beban pajak, membayar pajak yang telah dihitung, dan melaporkan pajak yang telah dihitung dan dibayar. Teknik pengambilan sampel menggunakan metode convenience sampling. Wajib pajak yang pada saat penelitian berlangsung berada di KPP Pratama Salatiga, diminta kesediaannya untuk mengisi instrument penelitian.

Penelitian ini menggunakan instrumen kuesioner yang sebagian besar diadopsi dan dikembangkan dari instrumen-instrumen yang telah digunakan pada penelitian terdahulu. Terdapat dua konstruk utama yaitu dimensi kualitas 
pelayanan dan kepatuhan wajib pajak serta satu konstruk intervening, yaitu kepuasan wajib pajak. Semua konstruk diukur menggunakan skala likert.

\section{Tabel 1. Indikator-Indikator Konstruk}

\begin{tabular}{|c|c|c|}
\hline Konstruk & Definisi Operasional & Indikator \\
\hline $\begin{array}{l}\text { Bukti Fisik } \\
(\xi 1)\end{array}$ & $\begin{array}{l}\text { Bagaimana para petugas pajak } \\
\text { mampu menunjukkan keberadaan } \\
\text { yang sebenarnya pada pihak } \\
\text { eksternal (Zeithaml, Valarie, Berry, } \\
\text { \& Leonard, 2003) }\end{array}$ & $\begin{array}{l}\text { Fasilitas fisik } \\
\text { Perlengkapan yang } \\
\text { dipergunakan } \\
\text { Peralatan dan teknologi yang } \\
\text { dipergunakan } \\
\text { Penampilan pegawai }\end{array}$ \\
\hline $\begin{array}{l}\text { Daya } \\
\text { Tanggap } \\
(\xi 2)\end{array}$ & $\begin{array}{l}\text { Sikap tanggap dalam membantu } \\
\text { pelanggan serta memberikan } \\
\text { pelayanan secara cepat dan tepat, } \\
\text { dengan cara penyampaian } \\
\text { informasi yang jelas (Zeithaml, } \\
\text { Valarie, Berry, \& Leonard, 2003) }\end{array}$ & $\begin{array}{l}\text { Kemauan pegawai untuk } \\
\text { segera membantu WP } \\
\text { Kemauan pegawai untuk } \\
\text { memberikan pelayanan yang } \\
\text { cepat } \\
\text { Kemauan pegawai untuk } \\
\text { memberikan pelayanan } \\
\text { secara tepat pegawai untuk } \\
\text { Kemauan pegai informasi } \\
\text { menyampaikan } \\
\text { yang jelas }\end{array}$ \\
\hline $\begin{array}{l}\text { Kehandalan } \\
(\xi 3)\end{array}$ & $\begin{array}{l}\text { Kemampuan untuk memberikan } \\
\text { pelayanan jasa yang telah dijanjikan } \\
\text { kepada wajib pajak secara tepat, } \\
\text { konsisten dan terpercaya } \\
\text { (Zeithaml, Valarie, Berry, \& } \\
\text { Leonard, 2003) }\end{array}$ & $\begin{array}{l}\text { Ketepatan waktu } \\
\text { Pelayanan yang sama untuk } \\
\text { semua WP } \\
\text { Sikap yang simpatik } \\
\text { Pelayanan dengan akurasi } \\
\text { yang tinggi }\end{array}$ \\
\hline $\begin{array}{l}\text { Jaminan } \\
(\xi 4)\end{array}$ & $\begin{array}{l}\text { Bagaimana cara menumbuhkan } \\
\text { rasa percaya pelanggan terhadap } \\
\text { kemampuan, kesopanan, dan } \\
\text { pengetahuan yang dimiliki setiap } \\
\text { pegawai (Zeithaml, Valarie, Berry, \& } \\
\text { Leonard, 2003) }\end{array}$ & $\begin{array}{l}\text { Pengetahuan pegawai } \\
\text { Kesopansantunan pegawai } \\
\text { Kemampuan pegawai } \\
\text { menumbuhkan rasa percaya } \\
\text { kepada KPP Pratama } \\
\text { Sifat para pegawai yang dapat } \\
\text { dipercaya }\end{array}$ \\
\hline $\begin{array}{l}\text { Empati } \\
(\xi 5)\end{array}$ & $\begin{array}{l}\text { Pemberian perhatian yang bersifat } \\
\text { individual seperti memahami } \\
\text { kebutuhan maupun keinginan } \\
\text { pelanggan (Zeithaml, Valarie, Berry, } \\
\text { \& Leonard, 2003) }\end{array}$ & $\begin{array}{l}\text { Kemudahan untuk } \\
\text { memanfaatkan pelayanan } \\
\text { Kemampuan pegawai } \\
\text { melakukan komunikasi } \\
\text { Kemauan pegawai untuk } \\
\text { memperoleh masukan dari } \\
\text { wajib pajak pegawai } \\
\text { Kemampuan } \\
\text { memberikan perhatian yang } \\
\text { bersifat pribadi kepada wajib } \\
\text { pajak }\end{array}$ \\
\hline
\end{tabular}


Tabel 2. Indikator-Indikator Konstruk (lanjutan)

\begin{tabular}{|c|c|c|}
\hline Konstruk & Definisi Operasional & Indikator \\
\hline $\begin{array}{l}\text { Kepuasan } \\
\text { Wajib Pajak } \\
(\eta 1)\end{array}$ & $\begin{array}{l}\text { Tanggapan pelanggan atas } \\
\text { evaluasi antara harapan dan } \\
\text { kinerja aktual produk setelah } \\
\text { pemakaiannya (Tjiptono, } \\
\text { 2007) }\end{array}$ & $\begin{array}{l}\text { Hubungan antara pihak pegawai } \\
\text { dan wajib pajak menjadi harmonis } \\
\text { Wajib pajak rajin dalam } \\
\text { membayar pajak } \\
\text { Memungkinkan terciptanya } \\
\text { rekomendasi dari mulut ke mulut } \\
\text { yang positif oleh wajib pajak } \\
\text { (word of mouth) }\end{array}$ \\
\hline $\begin{array}{l}\text { Kepatuhan } \\
\text { Wajib Pajak } \\
(\eta 2)\end{array}$ & $\begin{array}{l}\text { Kesediaan para wajib pajak } \\
\text { untuk memenuhi kewajiban } \\
\text { perpajakannya sesuai aturan } \\
\text { yang berlaku tanpa diperlukan } \\
\text { adanya investigasi, peringatan, } \\
\text { pemeriksaan, serta penerapan } \\
\text { sanksi baik hukum maupun } \\
\text { sanksi administrasi ( James et } \\
\text { al, 2005) }\end{array}$ & $\begin{array}{l}\text { Wajib pajak paham maupun } \\
\text { bersedia untuk memahami } \\
\text { semua ketentuan peraturan } \\
\text { perundang-undangan } \\
\text { perpajakan } \\
\text { Mengisi formulir pajak secara } \\
\text { lengkap dan jelas } \\
\text { Menghitung secara benar jumlah } \\
\text { pajak yang terutang } \\
\text { Membayar secara tepat waktu }\end{array}$ \\
\hline
\end{tabular}

Pengolahan data dilakukan dengan Smart PLS (Partial Least Square). PLS dapat secara simultan melakukan pengujian model pengukuran serta pengujian model struktural yang merupakan analisis persamaan struktural (SEM) berbasis varian. Sebelum dilakukan pengujian atas hipotesis yang diajukan, terlebih dahulu dilakukan pengujian atas kualitas data yang terdiri dari uji validitas data, uji reliabilitas, uji inner model. Uji validitas data dilakukan untuk memastikan bahwa kuisioner mampu menangkap apa yang akan diukur.

Parameter uji validitas konstruk dalam pengukuran PLS adalah pertama, rule of thumbs parameter uji validitas konvergen adalah loading factor $\geq 0.70$, namun demikian pengembangan skala pengukuran nilai loading 0,50 sampai 0,60 dianggap cukup sebagai penelitian pada tahap awal. Kriteria validitas juga dapat dilihat dari nilai Average Variance Extracted (AVE) dari masing-masing konstruk. Konstruk dikatakan memiliki validitas yang tinggi jika nilai AVE $\geq$ 0,50 . Pengukuran reliabilitas dilakukan dengan melihat nilai cronbach alpha yang berada diatas 0,6 , nilai composite reliability diatas 0,70 . Sementara pengujian inner model dilakukan dengan melihat nilai nilai Goodness of Fit (GoF). GoF merupakan suatu ukuran yang digunakan untuk memvalidasi performa gabungan antar model pengukuran dan model struktural. Nilai GoF berkisar antara 0 sampai 1 dengan ketentuan kriteria, 0,10 (small), 0,25 (medium), dan 0,36 (large) (Tenenhaus, Vinzi, Chatelin, \& Lauro, 2005). GoF dapat dihitung dengan menggunakan persamaan

$G o F=\sqrt{\bar{A}} \overline{\bar{E}} E \times \overline{\bar{R}}^{2}$ 


\section{Hasil dan Pembahasan}

\section{Profil Responden Penelitian}

Responden dalam penelitian ini adalah wajib pajak orang pribadi usahawan atau pekerjaan bebas yang terdaftar di KPP Pratama Salatiga sebanyak 125 orang responden.

Tabel 3. Profil Responden

\begin{tabular}{lcc}
\hline Keterangan & Frekuensi & Persentase \\
\hline Jenis Kelamin & & \\
$\quad$ Laki-laki & 73 & $58 \%$ \\
$\quad$ Perempuan & 52 & $42 \%$ \\
Kelompok Umur & & \\
Antara 20 sampai 30 tahun & 40 & $32 \%$ \\
Antara 31 sampai 40 tahun & 53 & $42 \%$ \\
Antara 41 sampai 50 tahun & 32 & $24 \%$ \\
Pendidikan Terakhir & & \\
SMA & 11 & $9 \%$ \\
S1 & 102 & $82 \%$ \\
S2 & 12 & $9 \%$ \\
\hline
\end{tabular}

Sumber: Data Primer 2016

Persentase responden berjenis kelamin laki-laki sebesar 58\% sedangkan persentase responden berjenis kelamin perempuan sebesar $42 \%$. Responden yang berumur antara 20 sampai 30 tahun sebanyak $32 \%$, yang berumur antara 31 sampai 40 tahun berjumlah 42\%. Sedangkan responden yang berumur 41 sampai 50 tahun sebanyak 24\%. Dari seluruh responden yang ada, responden yang berpendidikan akhir perguruan tinggi S1 memiliki persentase terbanyak yaitu sebesar $82 \%$.

\section{Statistik Deskriptif}

Statistik deskriptif memberikan gambaran atau deskripsi suatu data yang dilihat dari nilai minimum, maksimum, rata-rata, dan standar deviasi. Tabel 3 menunjukkan bahwa rata-rata jawaban responden adalah lebih dari 3 untuk semua konstruk yaitu bukti fisik, daya tanggap, kehandalan, jaminan dan empati, kepuasan wajib pajak dan kepatuhan wajib pajak. Hal ini menunjukkan bahwa responden menerima bukti fisik, sikap tanggap, kehandalan, jaminan, dan empati yang cukup baik dari pegawai KPP Pratama serta memiliki kepuasan yang tinggi atas pelayanan yang diberikan dan memiliki kepatuhan yang tinggi akan kewajiban perpajakannya. 
Tabel 4. Statistik Deskriptif Konstruk

\begin{tabular}{|c|c|c|c|c|c|}
\hline Konstruk & Indikator & Min & Maks & Mean & $\begin{array}{c}\text { Std. } \\
\text { Deviasi }\end{array}$ \\
\hline \multirow[t]{4}{*}{ Bukti Fisik } & Kelengkapan pelayanan & 2 & 5 & 3,540 & 0,941 \\
\hline & Penampilan pegawai & 2 & 5 & 3,620 & 0,946 \\
\hline & Rata-rata & & & & 0,944 \\
\hline & & & & 3,580 & \\
\hline \multirow[t]{5}{*}{ Daya Tanggap } & Pemberian bantuan & 2 & 5 & 3,440 & 0,864 \\
\hline & Pelayanan cepat & 2 & 5 & 3,440 & 0,898 \\
\hline & Pelayanan tepat waktu & 2 & 5 & 3,510 & 0,922 \\
\hline & Rata-rata & & & & 0,895 \\
\hline & & & & 3,463 & \\
\hline \multirow[t]{5}{*}{ Kehandalan } & Jadwal tepat waktu & 2 & 5 & 3,470 & 0,921 \\
\hline & Pelayanan yang setara & 2 & 5 & 3,630 & 0,966 \\
\hline & Sikap simpatik & 2 & 5 & 3,500 & 0,985 \\
\hline & Rata-rata & & & & 0,957 \\
\hline & & & & 3,533 & \\
\hline \multirow[t]{4}{*}{ Jaminan } & Pengetahuan baik & 2 & 5 & 3,460 & 0,943 \\
\hline & Kemampuan pelayanan baik & 2 & 5 & 3,530 & 0,866 \\
\hline & Rata-rata & & & & 0,905 \\
\hline & & & & 3,495 & \\
\hline \multirow[t]{5}{*}{ Empati } & Sikap tulus & 2 & 5 & 3,660 & 0,951 \\
\hline & Menerima kritik dan saran & 2 & 5 & 3,500 & 0,954 \\
\hline & Masukan secara pribadi & 2 & 5 & 3,470 & 0,953 \\
\hline & Rata-rata & & & & 0,953 \\
\hline & & & & 3,543 & \\
\hline Kepuasan & Informasi tersedia & 2 & 5 & 3,490 & 0,964 \\
\hline \multirow{4}{*}{ Wajib Pajak } & Bersedia merekomendasikan & 2 & 5 & 3,500 & 0,933 \\
\hline & Pelayanan sesuai harapan & 2 & 5 & 3,720 & 0,970 \\
\hline & Rata-rata & & & & 0,956 \\
\hline & & & & 3,570 & \\
\hline Kepatuhan & Melakukan koreksi ulang & 2 & 5 & 3,480 & 0,954 \\
\hline \multirow[t]{6}{*}{ Wajib Pajak } & Mengakui semua pendapatan & 2 & 5 & 3,440 & 0,952 \\
\hline & Taat menyampaikan SPT Masa & 2 & 5 & 3,710 & 0,962 \\
\hline & Taat menyampaikan SPT & 2 & 5 & 3,520 & 0,964 \\
\hline & Tahunan & & & & \\
\hline & Rata-rata & & & & 0,958 \\
\hline & & & & 3,537 & \\
\hline
\end{tabular}

Sumber: Data primer 2016

\section{Evaluasi Kualitas Data}

Pengujian model pengukuran digunakan untuk validasi model penelitian yang dibangun. Dua parameter utama yang dibangun adalah pengujian validitas konstruk (validitas konvergen dan validitas diskriminan) dan pengujian reliabilitas konstruk. Berikut ini adalah tabel output literasi algoritma. 
Tabel 5. Hasil Algoritma

\begin{tabular}{lcccc}
\hline \multicolumn{1}{c}{ Konstruk } & AVE & $\begin{array}{c}\text { Composite } \\
\text { Reliability }\end{array}$ & $\mathbf{R}^{\mathbf{2}}$ & $\begin{array}{c}\text { Cronbach's } \\
\text { Alpha }\end{array}$ \\
\hline Bukti Fisik & 0,861 & 0,925 & & 0,854 \\
Daya Tanggap & 0,575 & 0,799 & & 0,671 \\
Kehandalan & 0,819 & 0,931 & & 0,889 \\
Jaminan & 0,702 & 0,823 & & 0,603 \\
Empati & 0,776 & 0,912 & & 0,877 \\
Kepuasan Wajib Pajak & 0,844 & 0,942 & 0,113 & 0,942 \\
Kepatuhan Wajib Pajak & 0,778 & 0,934 & 0,949 & 0,934 \\
\hline
\end{tabular}

Validitas konstruk terdiri atas validitas konvergen dan validitas diskriminan. Validitas konvergen berhubungan dengan prinsip bahwa pengukur dari suatu konstruk berkorelasi tinggi. Jika nilai loading antara $0,50-0,70$, sebaiknya tidak menghapus indikator yang memiliki skor loading tersebut sepanjang nilai Average Variance Extracted (AVE) indikator tersebut $>0,50$. Hasil uji validitas konvergen adalah nilai outer loading factor seluruh konstruk yang digunakan adalah $>0,7$, AVE seluruh konstruk yang digunakan adalah $>0,5$.

Hasil uji reliabilitas menunjukkan bahwa nilai cronbach's alpha $>0,60$ dan nilai composite realibility $>0,70$ untuk seluruh konstruk yang digunakan. Dengan demikian dapat disimpulkan bahwa instrumen yang digunakan dalam penelitian ini reliabel.

Pada penelitian ini nilai $R$-squared untuk Kepuasan Wajib Pajak adalah 0,066 $(6,6 \%)$ dan Kepatuhan Wajib Pajak adalah 0,945 (94,5\%). Rata-rata R² adalah 0,505 dan rata-rata untuk seluruh AVE adalah 0,765. Menggunakan persamaan (1) diatas maka hasil dari perhitungan GoF untuk model penelitian ini yaitu sebesar 0,442 yang berarti bahwa model dalam penelitian ini adalah fit.

\section{Pengujian Hipotesis}

Pengujian hipotesis dilakukan terhadap dua kriteria hipotesis yaitu hipotesis yang menguji pengaruh langsung dimensi kualitas pelayanan terhadap kepuasan wajib pajak dan kepatuhan wajib pajak (hipotesis utama) dan pengujian pengaruh tidak langsung yaitu pengaruh dimensi kualitas pelayanan terhadap kepatuhan wajib pajak dengan medasi kepuasan wajib pajak (hipotesis efek mediasi).

Dari hasil pengujian hiptesis, menunjukkan nilai original sampel adalah 0.168 dan nilai signifikansi 0.016 sehingga dapat disimpulkan bahwa terdapat pengaruh positif yang signifikan antara dimensi kualitas pelayanan bukti fisik terhadap kepatuhan wajib pajak. Dengan demikian $\mathrm{H}_{1 a}$ yang menyatakan dimensi kualitas pelayanan bukti fisik berpengaruh secara langsung terhadap kepatuhan wajib pajak dapat didukung. Hipotesis $1 \mathrm{~b}\left(\mathrm{H}_{1 \mathrm{~b}}\right)$ yang menyatakan 
dimensi kualitas pelayanan daya tanggap berpengaruh secara langsung terhadap kepatuhan wajib pajak dalam pengujian hipotesis juga dapat didukung. Hal ini terbukti dari nilai original sampel sebesar 0.121 dan nilai signifikansi 0.014 .

Tabel 6. Pengujian Hipotesis

\begin{tabular}{|c|c|c|c|c|c|}
\hline \multicolumn{6}{|c|}{ Panel A. Pengujian Hipotesis Utama } \\
\hline & $\begin{array}{c}\text { Original } \\
\text { Sample (0) }\end{array}$ & $\begin{array}{c}\text { Sample } \\
\text { Mean (M) }\end{array}$ & $\begin{array}{c}\text { Standard } \\
\text { Error } \\
\text { (SERR) }\end{array}$ & $\begin{array}{l}\text { T Statistics } \\
(\mid 0 / \text { SERR } \mid)\end{array}$ & P Values \\
\hline KS -> KP & -0.007 & -0.007 & 0.020 & 0.358 & 0.721 \\
\hline \multirow{2}{*}{$\mathrm{BF}->\mathrm{KP}$} & 0.168 & 0.172 & 0.047 & 2.208 & \\
\hline & & & & & $0.016^{* *}$ \\
\hline $\mathrm{BF}->\mathrm{KS}$ & -0.314 & -0.231 & 0.284 & 1.106 & 0.271 \\
\hline \multirow[t]{2}{*}{$\mathrm{DT}->\mathrm{KP}$} & 0.121 & 0.120 & 0.049 & 2.492 & \\
\hline & & & & & $0.014^{* *}$ \\
\hline DT $->\mathrm{KS}$ & 0.058 & 0.025 & 0.166 & 0.349 & 0.728 \\
\hline $\mathrm{KH}->\mathrm{KP}$ & 0.756 & 0.758 & 0.042 & 18.112 & $0.000^{* * *}$ \\
\hline \multirow[t]{2}{*}{$\mathrm{KH}->\mathrm{KS}$} & -0.314 & -0.324 & 0.133 & 2.372 & \\
\hline & & & & & $0.020^{* *}$ \\
\hline $\mathrm{JA}->\mathrm{KP}$ & 0.158 & 0.157 & 0.044 & 3.545 & $0.001^{* * *}$ \\
\hline $\mathrm{JA}->\mathrm{KS}$ & 0.109 & 0.156 & 0.198 & 0.551 & 0.583 \\
\hline \multirow[t]{2}{*}{$\mathrm{EM}->\mathrm{KP}$} & 0.146 & 0.149 & 0.045 & 1.713 & \\
\hline & & & & & $0.028 * *$ \\
\hline $\mathrm{EM}->\mathrm{KS}$ & 0.481 & 0.398 & 0.315 & 1.526 & 0.130 \\
\hline \multicolumn{6}{|c|}{ Panel B. Pengujian Efek Mediasi } \\
\hline & $\begin{array}{c}\text { Original } \\
\text { Sample (0) }\end{array}$ & $\begin{array}{c}\text { Sample } \\
\text { Mean (M) }\end{array}$ & $\begin{array}{c}\text { Standard } \\
\text { Error } \\
\text { (SERR) }\end{array}$ & $\begin{array}{l}\text { T Statistics } \\
(\mid 0 / \text { SERR } \mid)\end{array}$ & P Values \\
\hline $\begin{array}{c}\mathrm{BF}->\mathrm{KS}- \\
>\mathrm{KP}\end{array}$ & 0.002 & 0.001 & 0.008 & 0.274 & 0.785 \\
\hline $\begin{array}{c}\text { DT->KS- } \\
>\text { KP }\end{array}$ & -0.000 & -0.000 & 0.004 & 0.103 & 0.918 \\
\hline $\mathrm{KH}>\mathrm{KS}->\mathrm{KP}$ & 0.002 & 0.002 & 0.007 & 0.335 & 0.738 \\
\hline $\mathrm{JA}>\mathrm{KS}->\mathrm{KP}$ & -0.001 & -0.001 & 0.005 & 0.164 & 0.870 \\
\hline $\begin{array}{c}\text { EM->KS- } \\
>\text { KP }\end{array}$ & -0.003 & -0.002 & 0.011 & 0.316 & 0.753 \\
\hline
\end{tabular}

Keterangan: BF: Bukti Fisik, DT: Daya Tanggap, KH: Kehandalan, JA: Jaminan, EM: Empati, KS: Kepuasan Wajib Pajak, KP: Kepatuhan Wajib Pajak

*** signifikan pada a $1 \%,{ }^{* *}$ signifikan pada a $5 \%$

Pengujian hipotesis 1c $\left(\mathrm{H}_{1 \mathrm{c}}\right)$ menunjukkan bahwa nilai original sampel sebesar 0.758 dan nilai signifikansi 0.000 yang berarti bahwa terdapat pengaruh positif yang signifikan antara dimensi kualitas pelayanan kehandalan dengan kepatuhan pajak. Dengan demikian dapat disimpulkan $\mathrm{H}_{1 \mathrm{c}}$ didukung. Sementara hipotesis $1 \mathrm{~d}\left(\mathrm{H}_{1 \mathrm{~d}}\right)$ yang menyatakan bahwa terdapat pengaruh langsung dimensi kualitas pelayanan jaminan terhadap kepatuhan wajib pajak memiliki nilai original sampel sebesar 0.158 dan nilai signifikansi 0.001 
sehingga dapat disimpulkan $\mathrm{H}_{1 \mathrm{~d}}$ didukung. Hasil yang sama juga ditunjukkan dalam pengujian hipotesis $1 \mathrm{e}\left(\mathrm{H}_{1 \mathrm{e}}\right)$ yang memiliki nilai original sampel sebesar 0.146 dan nilai signifikasni 0.028 . Hal ini berarti bahwa terdapat pengaruh positif yang signifikan antara dimensi kualitas pelayanan empati dengan kepatuhan pajak, sehingga $\mathrm{H}_{1 \mathrm{e}}$ dapat didukung.

Tabel 5 panel B dalam pengujian mediasi menunjukkan bahwa hipotesis 2a $\left(\mathrm{H}_{2 \mathrm{a}}\right)$ memiliki nilai original sampel sebesar 0.002 dan nilai signifikansi 0.785 . Nilai signifikansi yang lebih dari 0.10 menunjukkan bahwa $\mathrm{H}_{2 a}$ yang menyatakan terdapat pengaruh dimensi kualitas pelayanan bukti fisik terhadap kepatuhan wajib pajak melalui kepuasan wajib pajak dengan kepuasan sebagai variable intervening tidak didukung. Hasil yang sama juga ditunjukkan dalam pengujian Hipotesis $2 \mathrm{~b}\left(\mathrm{H}_{2 \mathrm{~b}}\right)$ yang memiliki nilai original sampel sebesar -0.000 dan nilai signifikansi 0.918. Dengan demikian $\mathrm{H}_{2 b}$ yang menyatakan bahwa terdapat pengaruh dimensi kualitas pelayanan daya tanggap terhadap kepatuhan wajib pajak melalui kepuasan wajib pajak tidak didukung. Hasil pengujian juga menunjukkan bahwa hipotesis $2 \mathrm{c}\left(\mathrm{H}_{2 \mathrm{c}}\right)$ tidak didukung karena memiliki nilai signifikansi 0.738 . Oleh sebab itu, tidak terdapat pengaruh dimensi kualitas pelayanan kehandalan terhadap kepatuhan wajib pajak melalui kepuasan wajib pajak.

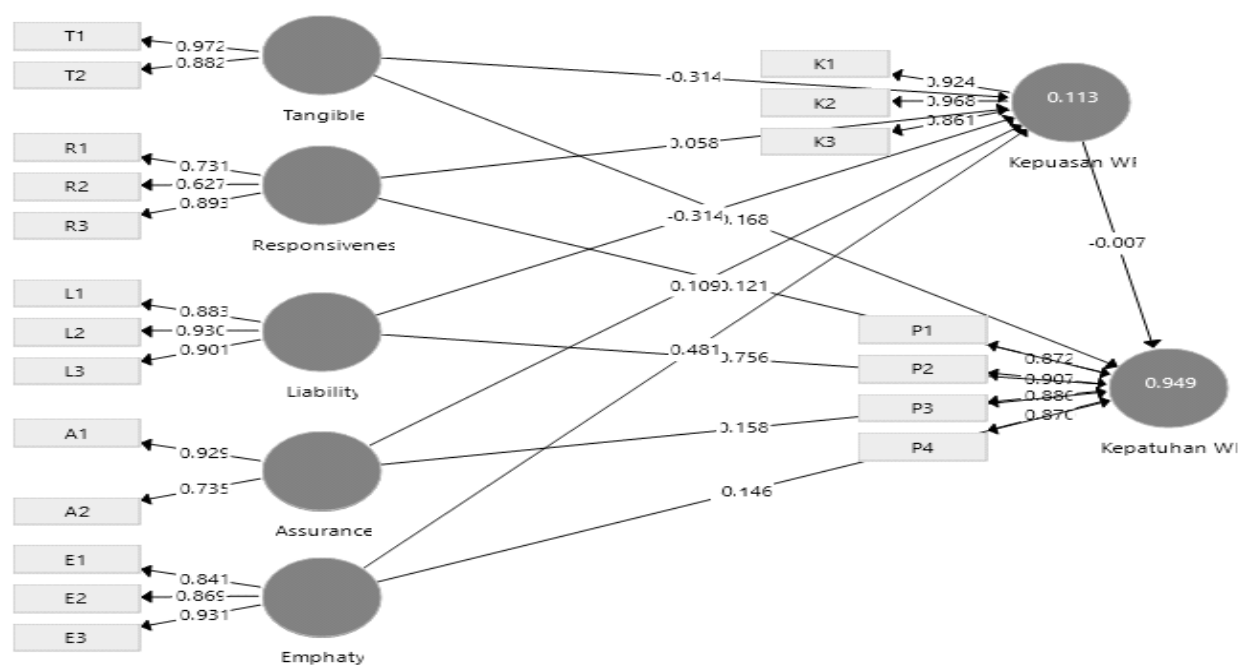

Gambar 2. Model Struktural

Sama dengan pengujian hipotesis dengan efek mediasi lainnya, Hipotesis $2 \mathrm{~d}$ $\left(\mathrm{H}_{2 \mathrm{~d}}\right)$ yang menyatakan bahwa terdapat pengaruh langsung dimensi kualitas pelayanan jaminan terhadap kepatuhan wajib pajak melalui kepuasan wajib pajak tidak didukung karena memiliki nilai nilai signifikansi 0.870 . Hipotesis terakhir yaitu hipotesis $2 \mathrm{e}\left(\mathrm{H}_{2 \mathrm{e}}\right)$ juga tidak dapat didukung karena memiliki nilai signifikansi 0.753 . Dengan demikian tidak terdapat pengaruh dimensi 
kualitas pelayanan empati terhadap kepatuhan wajib pajak melalui kepuasan wajib pajak.

\section{Pembahasan}

Hasil penelitian ini membuktikan bahwa kelima dimensi kualitas pelayanan bukti fisik, daya tanggap, kehandalan, jaminan, dan empati berpengaruh secara langsung terhadap kepatuhan wajib pajak. Hal ini sejalan dengan penelitian yang dilakukan oleh Mustaphaa \& Obid (2014); Nurhayati, Halimatusadiah, \& Diamonalisa (2015); Worsham \& Ronald (2006) yang mengungkapkan bahwa kualitas pelayanan pajak berpengaruh positif dan signifikan terhadap kepatuhan wajib pajak. Albari (2009) juga menunjukkan bahwa kualitas pelayanan memiliki pengaruh positif terhadap kepatuhan. Hal ini berarti kualitas pelayanan pajak yang baik dari instansi pajak dapat menjadi modal utama dan menjadi hal yang penting untuk dapat menarik perhatian para wajib pajak. Pelayanan pajak berupa fasilitas fisik dan pelayanan dari petugas pajak yang baik dapat membuat tingkat kepatuhan wajib pajak meningkat. Fasilitas fisik seperti ruang tunggu, tempat parkir yang cukup luas, formulir pajak yang tersedia secara lengkap membuat wajib pajak merasa nyaman saat berada di kantor pajak.

Selain fasilitas fisik yang nyaman, berbagai macam kegiatan yang mendukung wajib pajak untuk dapat lebih mudah melaksanakan kewajibannya membayar pajak antara lain petugas pajak cakap dalam menindaklanjuti pengaduan dari masyarakat, petugas pajak cepat tanggap dalam membantu menyelesaikan persoalan yang dihadapi wajib pajak terkait dengan pajak, petugas pajak memberikan pelayanan terbaik dalam memberikan kemudahan dalam pelayanan pajak, serta petugas pajak yang dapat menjunjung tinggi integritas, akuntabilitas, dan transparansi dapat menimbulkan kepercayaan dari wajib pajak. Apabila sudah terdapat kepercayaan dari wajib pajak, maka wajib pajak tidak lagi merasa enggan untuk melaksanakan kewajibnannya membayar pajak. Semakin tinggi kualitas pelayanan pajak akan semakin meningkatkan kepatuhan wajib pajak.

Hasil penelitian ini tidak dapat membuktikan bahwa ketika seluruh dimensi kualitas pelayanan tersebut terpenuhi secara baik maka akan menyebabkan rasa puas, kemudian rasa puas inilah nantinya yang menyebabkan kepatuhan. Penelitian ini membuktikan bahwa tidak terdapat pengaruh langsung dimensi kualitas pelayanan terhadap kepatuhan wajib pajak melalui kepuasan wajib pajak. Hasil penelitian ini bertentangan dengan penelitian yang dilakukan oleh Silalahi, Musadieq \& Nurtjahjono (2015) bahwa variabel kualitas pelayanan perpajakan mempunyai pengaruh signifikan terhadap kepuasan wajib pajak dan kualitas pelayanan perpajakan mempunyai pengaruh signifikan terhadap 
kepatuhan wajib pajak. Perbedaan penelitian Silalahi, Musadieq \& Nurtjahjono (2015) dengan penelitian ini dikarenakan pada penelitian Silalahi, Musadieq \& Nurtjahjono (2015) pengaruh kualitas pelayanan langsung dikaitkan terhadap kepuasan wajib pajak dan kepatuhan wajib pajak, sedangkan dalam penelitian ini menggabungkan variabel dimensi kualitas pelayanan, kepatuhan wajib pajak, serta kepuasan wajib pajak secara bersamaan, penelitian dengan penggabungan seperti ini tergolong baru sehingga terdapat sedikit perbedaan dalam pengujiannya.

Jika dimensi kualitas pelayanan tersebut tidak berpengaruh terhadap kepatuhan wajib pajak melalui kepuasan, hal ini menunjukkan bahwa faktor internal yang mempengaruhi sikap dan perilaku membayar pajak masyarakat Indonesia yang dapat merasakan kepuasan tidak memiliki pengaruh terhadap perilaku mereka untuk semakin patuh membayar pajak.

\section{Simpulan}

Dari hasil penelitian ini dapat disimpulkan bahwa terdapat pengaruh langsung dimensi kualitas pelayanan bukti fisik, dimensi kualitas pelayanan daya tangga, dimensi kualitas pelayanan kehandalan, dimensi kualitas pelayanan jaminan, dan dimensi kualitas pelayanan empati terhadap kepatuhan wajib pajak. Hal ini berarti apabila aparatur pajak memberikan pelayanan prima dengan mengandalkan dimensi kualitas pelayanan maka wajib pajak senantiasa akan patuh dalam memenuhi kewajibannya. Penelitian ini juga membuktikan bahwa tidak terdapat pengaruh dimensi kualitas pelayanan terhadap kepatuhan wajib pajak melalui kepuasan wajib pajak. Kepuasan wajib pajak tidak terbukti sebagai mediasi antara dimensi kualitas pelayanan terhadap kepatuhan wajib pajak. Rasa puas yang dimiliki seseorang ketika menerima pelayanan tidak membuat seseorang menjadi patuh.

Dari kelima dimensi pelayanan, variabel yang paling dominan adalah kehandalan yang dibuktikan dengan sample mean tertinggi Tanpa mengabaikan dimensi pelayanan lainnya, hendaknya KPP Pratama Salatiga memberikan perhatian lebih terhadap variabel kehandalan. Dengan demikian diharapkan wajib pajak akan patuh dan akan meningkatkan penerimaan pajak negara jika wajib pajak dapat menjalankan kewajibannya dengan baik dan patuh.

Keterbatasan studi ini adalah tidak dapat membuktikan kebaharuan penelitian bahwa variabel kepuasan merupakan variabel mediasi antara dimensi pelayanan terhadap kepatuhan pajak. Variabel kepuasan merupakan adopsi dari ilmu pemasaranoleh sebab itu perlu melakukan desain ulang atas indikator atas kepuasan pajak yang lebih sesuai dengan konteks perpajakan. 


\section{Daftar Pustaka}

Albari. (2009). Pengaruh Kualitas Layanan Terhadap Kepatuhan Membayar Pajak. Jurnal Siasat Bisnis, 1-13.

Awaluddin, I., \& Tamburaka, S. (2017). The Effect of Service Quality and Taxpayer Satisfaction on Compliance Payment Tax Motor Vehicles at Office One Roof System in Kendari. The International Journal of Engineering and Science, 6(11), $2319-1805$

Direktorat Jendral Pajak. (2008). Modernisasi Administrasi Perpajakan:Laporan Tahunan 2007. Jakarta: Departemen Keuangan Republik Indonesia.

Enni Savitri, M. (2016). The Effect of Taxpayer Awareness, Tax Socialization, Tax Penalties, Compliance Cost at Taxpayer Compliance with Service Quality as Mediating Variable. Social and Behavioral Sciences, 219, 682-687.

Fasmi, L., \& Misra, F. (2014). Modernisasi Sistem Administrasi Perpajakan dan Tingkat Kepatuhan Pengusaha Kena Pajak. Jurnal Akuntansi Multiparadigma, 5(1), 7687.

Feld, L. P., \& Frey, B. S. (2002). Trust Breeds Trust: How Taxpayers are Treated Working Paper No. 98. Zurich: Institute For Empiricial Research in Economics University of Zurich.

Frecknall-Hughes, J., \& Moizer, P. (2015). Assessing the quality of services provided by UK tax practitioners. eJournal of Tax Research, 13(1), 51-75.

Gasperzs, V. (1997). Manajemen Kualitas : Penerapan Konsep Kualitas Dalam Manajemen Bisnis Total. Jakarta: Gramedia.

Irena, F. (2014). Faktor-faktor yang Mempengaruhi Kepatuhan Wajib Pajak Orang Pribadi yag Melakukan Kegiatan Usaha di Pasar Kapasan Surabaya. Retrieved Mei 20, 2017, from http://repository.wima.ac.id

Jaya, A., Ratnawati, T., \& Sardjono, S. (2017). Analysis of Effect of Knowledge and Service Quality, Accessibility of Information, Awareness and Behavior of Taxpayers and Impact on Satisfaction and Compliance With Taxpayers of Land and Buildings in The City Batam Island Riau Province. International Journal of Business and Management Invention, 6(8), 73-83.

Kotler, P. (2003). Manajemen Pemasaran (Milenium ed.). (H. Teguh, R. Rusli, \& B. Molan, Trans.) Jakarta: PT Prenhallindo.

Mustaphaa, B., \& Obid, S. N. (2014). Tax Service Quality: The Mediating Effect of Perceived Ease of Use of the Online Tax System. Procedia - Social and Behavioral Sciences, 2-9.

Nurhayati, N., halimatusadiah, E., \& Diamonalisa. (2015). Influence of tax officer service quality and knowledge of tax on individual taxpayer compliance in tax office (kpp) Bojonagara Bandung. International Journal of Applied Research, 1(8), 805-809.

Silalahi, S., Musadieq, M. A., \& Nurtjahjono, G. E. (2015). Pengaruh Kualitas Pelayanan Perpajakan Terhadap Kepuasan Wajib Pajak, Kepatuhan Wajib Pajak dan Penerimaan Pajak. Jurnal Perpajakan (JEJAK).

Supadmi, N. L. (2009). Meningkatkan Kepatuhan Wajib Pajak Melalui Kualitas Pelayanan. Retrieved Mei 15, 2017, from http://jurnal.pdii.lipi.go.id 
Sutopo, \& Suryanto, A. (2003). Pelayanan Prima. Jakarta: LAN-RI.

Tenenhaus, M., Vinzi, V. E., Chatelin, Y.-M., \& Lauro, C. (2005). PLS Path Modeling. Computational Statistics \& Data Analysis, 48, 159-205.

Tjiptono, F. (2007). Pemasaran Jasa. Malang: Bayumedia Publishing.

Walsh, K. (2012). Understanding Taxpayer Behaviour -New Opportunities for Tax Administration. The Economic and Social Review, 43(3).

Worsham, J., \& Ronald, G. (2006). The Effect of Tax Authority Behavioron Tax Payer Compliance: A Procedural Justice Approach. Journal of American Taxation, 18(2), 19-39.

Zeithaml, Valarie, A., Berry, P. d., \& Leonard. (2003). Delivering Quality Service Balancing Costumer Perceptions And Expectations. New York: The Free Press A Division Of Mac Milan, Inc. 